\title{
Gestational weight gain and its associated factors in Harari Regional State: Institution based cross-sectional study, Eastern Ethiopia
}

Fekede Asefa $^{1 *}$ and Dereje Nemomsa ${ }^{2}$

\begin{abstract}
Background: Gestational weight gain is an important factor that supports optimal outcome for mothers and their infant. Whereas women who do not gain enough weight during pregnancy have a risk of bearing a baby with low birth weight, those who gain excessive weight are at increased risk of preeclampsia and gestational diabetes. Nonetheless, data on gestational weight gain and its determinants are scarce in developing countries, as it is difficult to collect the information throughout the pregnancy period. Therefore, the aim of the study was to assess weight gain during pregnancy and its associated factors.

Methods: The study employed a health facility based quantitative cross-sectional study design in Harari Regional State. The study included 411 women who had given birth at health institutions from January to July of 2014. The researchers collected both primary and secondary data by using a structured questionnaire and a checklist. Using logistic regression, the factors associated with gestational weight gain were assessed and, based on the United States Institute of Medicine criteria, gestational weight gains were categorized as inadequate, adequate and excessive.
\end{abstract}

Results: The study revealed that $69.3 \%, 28 \%$, and $2.7 \%$ of the women gained inadequate, adequate and excess gestational weight, respectively. The mean gestational weight gain was 8.96 (SD \pm 3.27$) \mathrm{kg}$. The factors associated with adequate gestational weight gain were body mass index $\geq 25 \mathrm{Kg} / \mathrm{m}^{2}$ at early pregnancy $(\mathrm{AOR}=3.2,95 \% \mathrm{Cl} 1.6$, 6.3); engaging in regular physical exercise ( $A O R=2.1,95 \% \mathrm{Cl} 1.2,3.6)$; Antenatal care visit of $\geq 4$ times ( $\mathrm{AOR}=2.9,95$ $\% \mathrm{Cl} 1.7,5.2)$; consuming fruit and vegetable $(\mathrm{AOR}=2.7,95 \% \mathrm{Cl} 1.2,6.6)$, and meat ( $\mathrm{AOR}=2.7,95 \% \mathrm{Cl} 1.1,97.2)$.

Conclusions: Generally, a small proportion of the women gained adequate gestational weight. The women who were with higher body mass index at early pregnancy, who frequently visited Antenatal care visit, and who consumed diverse food items were more likely to measure adequate gestational weight.

Keywords: Gestational weight gain, Early pregnancy BMI, Recommended GWG

Abbreviations: ANC, Antenatal care; AOR, Adjusted odds ratio; BMI, Body mass index; Cl, Confidence interval; COR, Crude odds ratio; GWG, Gestational weight gain; IOM, Institute of medicine; IRERC, Institutional Research and Ethical Review Committee; SD, Standard deviation; SPSS, Statistical package for social science

\footnotetext{
* Correspondence: sinboona@gmail.com

'Department of public Health, College of Health and Medical Sciences,

Haranmaya University, Dire dawa, Ethiopia

Full list of author information is available at the end of the article
} 


\section{Plain english summary}

Gestational weight gain is an important factor that is required to support increased metabolic demands, and to enhance positive pregnancy outcomes. A desirable gestational weight gain is essential for a balanced optimal outcome for both the mother and her infant. In contrast, inadequate or excessive weight gain may pose health risks on the mother and/or the fetus.

The study included 411 women who had given birth at health institutions from January to July of 2014. The researchers collected both primary and secondary data by using a structured questionnaire and a checklist. Based on the United States Institute of Medicine criteria, gestational weight gains were categorized as inadequate, adequate and excessive.

The study revealed that $69.3 \%, 28 \%$, and $2.7 \%$ of the women gained inadequate, adequate and excess gestational weight, respectively. The average gestational weight gain was $8.96 \mathrm{~kg}$. The factors associated with adequate gestational weight gain were high body mass index at early pregnancy; engaging in regular physical activity; Antenatal care visit of $\geq 4$ times; consuming fruit and vegetable, and meat.

Generally, a small proportion of the women gained adequate gestational weight. The women who were with higher body mass index at early pregnancy, who frequently visited Antenatal care visit, and who consumed diverse food items were more likely to measure adequate gestational weight.

\section{Background}

Gestational weight gain (GWG) is an important factor that is required to support increased metabolic demands, and to enhance positive pregnancy outcomes [1]. A desirable GWG is essential for a balanced optimal outcome for both the mother and her infant [2]. It supports the growth and development of the fetus [3], and reduces the likelihood of morbidity and mortality [2, 4]. In contrast, inadequate or excessive weight gain may pose health risks on the mother and/or the fetus [5].

GWG is highly influenced by a range of biological, metabolic, and social factors, which include maternal pre-pregnancy body mass index (BMI) [6], multi-parity $[6,7]$, maternal age, smoking, educational status [3], healthy eating, physical activity [2], and adequate counseling of mothers on weight gain during pregnancy [8]. However, in developing countries, there is very little information about GWG and its determinants. This is most likely due to the difficulties associated with collecting the data throughout the pregnancy period in these settings [9], and as such GWG remains a neglected public health issue in the developing world. Therefore, the aim of this study was to assess GWG and its associated factors in the health care facilities in Harari Regional State, Eastern Ethiopia.

\section{Methods \\ Study setting}

The study was conducted in Harari Regional State, whose capital, Harar, lies $526 \mathrm{~km}$ to the East of Addis Ababa. According to 2015 Ethiopian Central Statistical Agency population projection, the region has a population of 232,000, of whom 127,600 (55\%) are urban dwellers. According to the Regional Health Bureau, the health service coverage of the region is $100 \%$. There are two public hospitals, one Federal Police Hospital, one Federal Defense Hospital, two private General hospitals, one Fistula Hospital, eight government health centers, 16 health posts, and one nongovernmental organization clinic. The health worker per 1,000-population ratio is 2.8 .

\section{Subjects}

We employed a health facility based quantitative crosssectional study from January to July of 2014. The study included Hiwot Fana Hospital, Jugal Hospital, Harar Federal Police Hospital, Family Guidance Association Harar Model Clinic, and Arategna Health Centre. The pregnant women who attended antenatal care (ANC) clinic during first trimester (started their ANC visit at $\leq 16$ weeks of gestation) and who gave live birth in the health care facilities were included in the study. Women with twin pregnancy were excluded. The target sample size was determined by Open Epi Version 2.3, by taking the proportion of the women who gained adequate gestational weight $(p=0.55)[10], 5 \%$ margin of error, $95 \%$ confidence level, and $10 \%$ non-response rate. The final sample size was 418. All the women who gave birth and fulfilled the inclusion criteria were included in the study until the required sample size was achieved.

\section{Measurements}

We collected both the primary and the secondary data through interview and checklists. Secondary data like initial maternal weight, gestational age, number of ANC visit, and parity were extracted from antenatal follow up registration card. The last maternal weight (just before delivery) was measured by digital weight scale with minimum clothing. A participants' first measured weight (before or at 16 weeks' gestation) was used as the proxy for her weight at conception. GWG is the difference between the last and the first measured maternal weight. The United States Institute of Medicine (IOM) classifies a healthy GWG of $12.5-18 \mathrm{~kg}, 11.5-16 \mathrm{~kg}, 7-11 \mathrm{~kg}$ and 5-9 kg for underweight, normal, overweight and obese women respectively. Accordingly, weight gains below and above these recommendations are considered inadequate and excessive [3]. Variables, which collected 
through interviewing, were socio-demographic and economic characteristics, dietary pattern/dietary habit and physical exercise. Women were asked for their average dietary habit and physical activity throughout pregnancy.

\section{Data quality control}

The questionnaire was pre-tested on 20 women in Dilchora Hospital at Dire Dawa (outside of the study area) and feedback was used to guide the modifications necessary to optimise the questionnaire. The data collectors (midwives) and the supervisors (health officers) were selected from the health facilities based on their qualifications and field data collection experience. They were given training on the objectives of the study, data collection methods, and field supervision. The supervisors and principal investigator checked data for completeness on daily basis.

\section{Data processing and analyses}

Data were entered into Epi-data Version 3.0 and analysed using SPSS 20 statistical packages. Frequencies, proportions, measures of central tendency, and dispersions were estimated to describe the variables. Crude odds ratios (COR) and adjusted odds ratios (AOR) were calculated to determine the association between the explanatory variables and GWG. The variables associated with the dependent variable in the bivariate analyses at $\mathrm{p} \leq 0.2$ were entered into multivariable logistic regression model. The total GWG was taken as the difference between the last measured weight (recorded just before delivery) and the first measured weight at early pregnancy (before or at first trimester). Based on the IOM criteria, GWG was categorised as inadequate, adequate and excessive. Eleven $(2.7 \%)$ respondents who gained excessive weight were excluded from the logistic regression analyses.

\section{Results}

\section{Socio-demographic characteristics}

Out of the 418 participants identified for the study, 411 were included in the study, which gives a response rate of $98.3 \%$. Their mean age was 25.2 (SD \pm 5.01 ) years, and $65.2 \%$ of them were between 20 and 29 years of age. Most of the respondents (94.6\%) were married, $25.8 \%$ were illiterate, $16.5 \%$ attended tertiary education, $44 \%$ were Oromo in ethnic, $55.2 \%$ were Muslim, $81 \%$ were urban residents, and $52.6 \%$ were homemakers. Eighty four percent of the respondents started ANC follow up between 8 and 12 weeks of gestational age (Table 1).

Eating habit and physical exercise of the respondents Only $16.5 \%$ of the women ate food at least three times a day during their current pregnancy, and $81.5 \%, 79.1 \%$,
Table 1 Socio-demographic characteristics of the respondents in Harari Regional state, $2014(n=411)$

\begin{tabular}{|c|c|c|}
\hline Variable & Frequency & percent \\
\hline \multicolumn{3}{|l|}{ Age group (year) } \\
\hline less than 20 & 49 & 11.9 \\
\hline $20-29$ & 268 & 65.2 \\
\hline$>29$ & 94 & 22.9 \\
\hline \multicolumn{3}{|l|}{ Marital status } \\
\hline Single & 18 & 4.4 \\
\hline Married & 389 & 94.6 \\
\hline Divorced & 2 & 0.5 \\
\hline Widowed & 2 & 0.5 \\
\hline \multicolumn{3}{|l|}{ Educational status } \\
\hline No formal education & 106 & 25.8 \\
\hline Primary and secondary & 237 & 57.7 \\
\hline Tertiary education & 68 & 16.5 \\
\hline \multicolumn{3}{|l|}{ Ethnicity } \\
\hline Amhara & 128 & 31.1 \\
\hline Oromo & 181 & 44 \\
\hline Gurage & 42 & 10.2 \\
\hline Harari & 35 & 8.5 \\
\hline Tigrai & 15 & 3.6 \\
\hline Others $^{\text {a }}$ & 10 & 2.4 \\
\hline \multicolumn{3}{|l|}{ Religion } \\
\hline Muslim & 227 & 55.2 \\
\hline Christian & 181 & 44 \\
\hline Others & 3 & 0.7 \\
\hline \multicolumn{3}{|l|}{ Residence } \\
\hline Rural & 78 & 19 \\
\hline Urban & 333 & 81 \\
\hline \multicolumn{3}{|l|}{ Occupational status } \\
\hline Homemaker & 216 & 52.6 \\
\hline Government employee & 80 & 19.5 \\
\hline Merchant & 49 & 11.9 \\
\hline Private employee & 28 & 6.8 \\
\hline Farmer & 23 & 5.6 \\
\hline Student & 7 & 1.7 \\
\hline Daily laborer & 8 & 1.9 \\
\hline \multicolumn{3}{|l|}{ Estimated income (USD) } \\
\hline Less than $\$ 50$ & 88 & 21.5 \\
\hline$\$ 50-\$ 100$ & 157 & 38.2 \\
\hline$>\$ 100$ & 166 & 40.3 \\
\hline \multicolumn{3}{|c|}{ Gestation age at ANC initiation } \\
\hline Less than 8 weeks & 39 & 9.5 \\
\hline 8-12 weeks & 345 & 83.9 \\
\hline 13-16 weeks & 27 & 6.6 \\
\hline
\end{tabular}

${ }^{\text {a }}$ Others - Somali, Walayita, Argoba 
and $91.7 \%$ of them consumed fruits and vegetables, meat, and egg at least once a week, respectively. During their current pregnancy, $65.2 \%$ were not engaged in any physical activities (Table 2).

Early pregnancy BMI and GWG of the study participants The mean BMI of the respondents at early pregnancy was $22.39\left(\mathrm{SD} \pm 3.84 \mathrm{~kg} / \mathrm{m}^{2}\right)$, and $72 \%$ of them had a normal body weight (BMI 18-24.9 kg/m2), whereas $14.6 \%$ were overweight (BMI 25-29.9 kg/m2). The mean weight gain during their pregnancy was 8.96 (SD $\pm 3.27 \mathrm{~kg}) \mathrm{kg}$. Underweight and obese women gained $9.14(\mathrm{SD} \pm 3.46 \mathrm{~kg}$ ) and $6.44(\mathrm{SD} \pm 3.46 \mathrm{~kg})$, respectively (Table 3). Many of the women (69.3\%) gained inadequate gestational weight, but only 11 (2.7\%) respondents gained excessive gestational weight. Based on early pregnancy BMI, only $7.7 \%$ of the underweight women, $24 \%$ of the women with normal BMI, $51.7 \%$ of the overweight women, and $62.5 \%$ of the obese women gained adequate gestational weight (Table 4).

\section{Factors associated with weight gain during pregnancy}

In a logistic regression model, the women who had higher early pregnancy BMI (overweight and obese) were more likely to gain adequate gestational weight as compared to the underweight mothers $(\mathrm{AOR}=3.2,95 \% \mathrm{CI}$ 1.6,6.3). The women who fed on fruit and vegetables $(\mathrm{AOR}=2.7,95 \% \mathrm{CI} 1.16,6.6)$, or meat $(\mathrm{AOR}=2.7,95 \%$ CI 1.1,7.2) at least once a week were more likely to gain adequate gestational weight than their counter parts, as were women who engaged in different physical activities

Table 2 Eating habit and physical exercise of the respondents during their current pregnancy in Harari Regional State, 2014 $(n=411)$

\begin{tabular}{|c|c|c|}
\hline Variable & Frequency & Percept \\
\hline \multicolumn{3}{|c|}{ Frequency of eating per day } \\
\hline$<3$ times & 343 & 83.5 \\
\hline$\geq 3$ times & 68 & 16.5 \\
\hline \multicolumn{3}{|c|}{ Frequency of eating vegetables and fruit at least once per week } \\
\hline Yes & 335 & 81.5 \\
\hline No & 76 & 18.5 \\
\hline \multicolumn{3}{|c|}{ Frequency of eating meat at least once per week } \\
\hline Yes & 325 & 79.1 \\
\hline No & 86 & 20.9 \\
\hline \multicolumn{3}{|c|}{ Frequency of eating egg at least once per week } \\
\hline Yes & 377 & 91.7 \\
\hline No & 34 & 8.3 \\
\hline \multicolumn{3}{|c|}{ Physical exercise at least once per week } \\
\hline Yes & 143 & 34.8 \\
\hline No & 268 & 65.2 \\
\hline
\end{tabular}

Table $3 \mathrm{BMl}$ at early pregnancy and mean gestational weight gain in Harari Regional state, $2014(n=411)$

\begin{tabular}{llcl}
\hline Early pregnancy BMI & Frequency (\%) & Mean GWG & SD \\
\hline$<18.5 \mathrm{~kg} / \mathrm{m}^{2}$ & $39(9.5)$ & $9.14 \mathrm{~kg}$ & $\pm 3.46 \mathrm{~kg}$ \\
$18.5-24.9 \mathrm{~kg} / \mathrm{m}^{2}$ & $296(72)$ & $9.26 \mathrm{~kg}$ & $\pm 3.14 \mathrm{~kg}$ \\
$25-29.9 \mathrm{~kg} / \mathrm{m}^{2}$ & $60(14.6)$ & $8.03 \mathrm{~kg}$ & $\pm 3.64 \mathrm{~kg}$ \\
$\geq 30 / \mathrm{m}^{2}$ & $16(3.9)$ & $6.44 \mathrm{~kg}$ & $\pm 3.46 \mathrm{~kg}$ \\
Total & $411(100)$ & $8.96 \mathrm{~kg}$ & $\pm 3.27 \mathrm{~kg}$ \\
\hline
\end{tabular}

$(\mathrm{AOR}=2.1,95 \%$ CI 1.2, 3.6). Likewise, women who gave birth at or after 37 weeks $(\mathrm{AOR}=4.5,95 \% \mathrm{CI} 1.1,20.7)$, or who had ANC follow up of $\geq 4$ times $(\mathrm{AOR}=2.9$, $95 \%$ CI 1.7, 5.1) were more likely to gain adequate gestational weight compared to their counterparts (Table 5).

\section{Discussion}

Adequate gestational weight gain is required for optimal pregnancy outcome. Less than one-third (28\%) of the pregnant women in this study gained adequate gestational weight. The factors positively associated with the adequate gain of the weight were having high BMI at early pregnancy $\left(\geq 25 \mathrm{~kg} / \mathrm{m}^{2}\right)$, engaging in regular physical exercise, visiting ANC frequently, and eating fruit, vegetables and meat.

In the study, the mean weight gain during pregnancy was $8.96 \mathrm{~kg}$. This is consistent with the findings from a study in Pakistan $(8.5 \mathrm{~kg})$ [11], but less than the findings from research in Brazil, in which the mean GWG ranged from 11.7 to $13.9 \mathrm{~kg}$ depending on BMI at early pregnancy [12-14]. Although the proportion of the women who gained inadequate $(69.3 \%)$ and adequate $(28 \%)$ gestational weight in our study is similar to those found in studies conducted in other countries $[15,16]$, it is smaller than the findings of similar studies conducted in other areas $[11,14,17,18]$. The inadequate gestational weight gain in our study is most likely related to the nutritional condition of the women, given that $84 \%$ of the women had less than three meals per day. In addition, a significant proportion of women were underweight at the conception. Moreover, while IOM recommendations

Table 4 Proportion of gestational weight gain of the women based on early pregnancy BMI in Harari Regional state, 2014 $(n=411)$

\begin{tabular}{llll}
\hline Early Pregnancy & $\begin{array}{l}\text { Inadequate GWG } \\
\text { BMl }\end{array}$ & $\begin{array}{l}\text { Adequate GWG } \\
N(\%)\end{array}$ & $\begin{array}{l}\text { Excess GWG } \\
N(\%)\end{array}$ \\
\hline Under weight & $35(89.7)$ & $3(7.7)$ & $1(2.6)$ \\
Normal & $222(75)$ & $71(24)$ & $3(1)$ \\
Overweight & $23(38.3)$ & $31(51.7)$ & $6(10)$ \\
Obese & $5(3.25)$ & $10(62.5)$ & $1(6.25)$ \\
Total & $285(69.3)$ & $115(28)$ & $11(2.7)$ \\
\hline
\end{tabular}


Table 5 Factors associated with gestational weight gain during pregnancy of Harari Regional State, $2014(N=400)$

\begin{tabular}{|c|c|c|c|c|}
\hline Variable & Adequate GWG & Inadequate GWG & $\operatorname{COR}(95 \%, \mathrm{Cl})$ & AOR $(95 \% \mathrm{Cl})$ \\
\hline \multicolumn{5}{|l|}{ Early pregnancy BMI } \\
\hline Underweight & $3(7.9)$ & $35(92.3)$ & 1.00 & 1.00 \\
\hline Normal & $71(24.2)$ & $222(75.8)$ & $17(4.7-61)^{*}$ & $7.9(1.9-34)^{* * *}$ \\
\hline Overweight\& obese & $41(59.4)$ & $28(41.6)$ & $4.6(2.6-7.9)^{* * *}$ & $3.2(1.6-6.3)^{*}$ \\
\hline \multicolumn{5}{|l|}{ Gestational age } \\
\hline$<37$ weeks & $2(3.7)$ & $52(96.3)$ & 1.00 & 1.00 \\
\hline$\geq 37$ weeks & $113(32.7)$ & $233(67.3)$ & $12.6(3-52)^{* *}$ & $4.5(1.1-20.7)^{*}$ \\
\hline \multicolumn{5}{|l|}{ ANC visit } \\
\hline$\leq 3$ & $29(14.9)$ & $166(85.1)$ & 1.00 & 1.00 \\
\hline$\geq 4$ & $86(42)$ & $119(58)$ & $4(2.5-6.7)^{* * *}$ & $2.9(1.7-5.2)^{* * *}$ \\
\hline \multicolumn{5}{|c|}{ Physical exercise per week } \\
\hline Not at all & $57(21.9)$ & $203(78.1)$ & 1.00 & 1.00 \\
\hline At least once & $58(41.4)$ & $82(58.6)$ & $2.5(1.6-3.9)^{* * *}$ & $2.1(1.2-3.6)^{*}$ \\
\hline \multicolumn{5}{|l|}{ Monthly Income status } \\
\hline$<\$ 50$ & $17(19.3)$ & $71(80.7)$ & 1.00 & 1.00 \\
\hline$\$ 50-\$ 100$ & $17(11.2)$ & $135(88.8)$ & $0.5(0.3-1.1)$ & $1.5(0.7-3.3)$ \\
\hline$>\$ 100$ & $81(50.6)$ & $79(49.4)$ & $2.7(1.4-5.2)^{* *}$ & $5.2(2.7-9.9)$ \\
\hline \multicolumn{5}{|c|}{ Frequency of eating a day } \\
\hline$<3$ times/day & $85(25.2)$ & $252(74.8)$ & 1.00 & 1.00 \\
\hline$\geq 3$ times/day & $30(47.6)$ & $33(52.4)$ & $2.6(1.6,4-68)^{* *}$ & $2.5(0.9-2.4)$ \\
\hline \multicolumn{5}{|c|}{ Fruit and vegetables consumption per week } \\
\hline Not at all & $9(12.2)$ & $65(87.8)$ & 1.00 & 1.00 \\
\hline At least once & $106(32.5)$ & $220(67.5)$ & $3.5(1.7-7.3)^{* *}$ & $2.7(1.2-6.6)^{*}$ \\
\hline \multicolumn{5}{|c|}{ Eggs consumption per week } \\
\hline Not at all & $5(15.2)$ & $28(84.8)$ & 1.00 & 1.00 \\
\hline At least once & $110(30)$ & $257(70)$ & $2.4(0.9,6.37)$ & $0.4(0.1,1.5)$ \\
\hline \multicolumn{5}{|c|}{ Meat consumption per week } \\
\hline Not at all & $9(10.7)$ & $75(89.3)$ & 1.00 & 1.00 \\
\hline At least once & $106(33.5)$ & $210(66.5)$ & $4(2.0-8.7)^{* * *}$ & $2.7(1.1-7.2)^{*}$ \\
\hline \multicolumn{5}{|l|}{ Residence } \\
\hline Rural & $15(21.4)$ & $55(78.6)$ & 1.00 & 1.00 \\
\hline Urban & $100(30.3)$ & $230(69.7)$ & $1.6(0.9-2.9)$ & $0.8(0.4-1.8)$ \\
\hline \multicolumn{5}{|l|}{ Parity } \\
\hline primipara & $54(25.5)$ & $158(74.5)$ & 1.00 & 1.00 \\
\hline Multi para & 61 (32.4) & $127(67.6)$ & $1.4(0.9-2.2)$ & $0.9(0.5-1.7)$ \\
\hline
\end{tabular}

may be well suited to high-income countries, there may be a number of contextual factors that limit the applicability of these guidelines to low or middle incomecountries such as Ethiopia. It is, therefore, important to consider GWG in the context of all the factors in a woman's life and to develop a GWG guideline that could address the context of developing countries.

This study also indicated that the women with higher early pregnancy BMI were more likely to gain adequate gestational weight when compared to underweight women. This is consistent with previous research in Pakistan [11]. Women who are underweight at early pregnancy are required to gain more weight than their overweight or obese counterparts do in order to achieve a healthy GWG. It may be difficult for these women to gain a significant amount of weight during pregnancy, particularly if they tend to be underweight due to metabolic or food security factors. Overweight and obese women, on the other hand, 
are required to gain comparatively little weight to achieve adequate GWG as they are able to use a portion of their stored energy to support the growth of the fetus. As such, adequate GWG may be attained easily for these women.

At least a half-an- hour of physical exercise per day is believed to be vital during pregnancy for a healthy lifestyle and for weight management for both the mother and the fetus [19]. In the study, the mothers who undertook physical exercise at least once a week were 2.1 times more likely to gain adequate gestational weight compared to those that did not. This finding is in line with other studies conducted in the United states [20] and China [21].

The women who frequently visited ANC ( $\geq 4$ times) were 2.9 times more likely to gain adequate gestational weight. This result supports the findings of the study in southern Brazil [15]. This may be explained by the fact that during ANC visits, women are likely to receive advice on weight management, the importance of maintaining a balanced diet, the need for proper nutrition during pregnancy. The women who gave birth at or after 37 weeks of gestation were 4.5 times more likely to have gained adequate gestational weight compared to than those who gave birth before 37 weeks. This is supported by research in Thailand [6], and may be attributed to an increased opportunity to gain weight by virtue of having an increase gestational period.

Women who eat fruit and vegetable for at least once per week were 2.7 times more likely to gain adequate gestational weight. This contrasts with finding of another study [20] in which fruit and vegetable consumption during pregnancy has no association with weight gain. The difference might be due to a small number of subjects (105) in the indicated study. However, in this study, $81.5 \%$ of the women consumed fruit and vegetable most of the day during their current pregnancy.

The women from good family income (family income of $>\$ 100$ per month) were 5 times more likely to gain adequate gestational weight than their counter parts, a finding supported by research in Southern Brazil [15]. It is likely that a good family income enhances household food security. In which case, pregnant women with a high family income are more likely to have consistent access to a varied diet and thus could gain appropriate weight during pregnancy.

This study has some limitations. Since the weight gain recommendation is the recommendation of developed countries, it may underestimate the proportion of gestational weight gain in developing countries such as Ethiopia, where this study was conducted. Moreover, early pregnancy BMI was taken before or at 16 weeks of gestation, at which time there may already have been an increase or decrease of gestational weight. Since variables like physical excersise and dietary habits were asked retrospectively, and they are qualitative in nature; it is difficult to measure objectively and does not indicate any specific trimester. Findings are also generalizable only for women who attended at least one ANC visit and gave birth at a health facility.

\section{Conclusions}

A considerable proportion of women in this study $(69.3 \%)$ gained inadequate gestational weight, while less than one-third ( $28 \%$ ) gained adequate gestational weight. Women with higher BMI at early pregnancy, who frequently visited $\mathrm{ANC}$, or who consumed diverse food items during pregnancy have higher likelihood of gaining recommended gestational weight. Therefore, women of childbearing age should be informed about the importance of conceiving at a normal BMI, maintaining a balanced diet, engaging in physical activity during pregnancy, and achieving a healthy gestational weight gain. There is also a need to develop guidelines on gestational weight gain to optimize pregnancy and birth outcomes in low- and middle-income countries.

\section{Acknowledgment \\ The authors would like to acknowledge Haramaya University for providing some technical support and ethically reviewing the paper. Next, we would like to thank the data collectors and the study participants. Our heartfelt thanks goes to Victoria Oliver (PhD) for reviewing the manuscript prior to submission. Finally, yet importantly, our thanks go to those individuals who directly or indirectly contributed their skills and knowledge toward the accomplishment of this study.}

\section{Availability of data and materials}

All important data and materials have already been included in the manuscript.

\section{Authors' contribution}

FA has critically revised the design of the study, data collection techniques, involved in the statistical analysis, and drafted the manuscript. DN has conceived the study, overall design and execution, performed data collection and statistical analysis. Both authors read this manuscript and finally approved for submission.

\section{Authors' information}

FA has Master of Public Health in Epidemiology, and currently serves as a lecturer and Head, Department of Public Health, Haramaya University. DN has Master of Public Health in Nutrition and currently working in Federal Police Hospital, Harar, Ethiopia.

\section{Competing interests}

The authors declare that they have no competing interests.

\section{Ethics approval and consent to participate}

The Institutional Research and Ethical Review Committee (IRERC) of the College of Health and Medical Sciences of Haramaya University approved the study protocol. Official letter of co-operation was written to each health institution. The participants were informed about the purposes and procedures of the data collection, and the potential risks and benefits of the study It was explained that participation would be voluntary, and that private information would be protected. A written informed consent was obtained from each participant. To strengthen confidentiality, the participants' names were excluded from the questionnaires, and participants were identified only through numerical codes. 


\section{Author details}

'Department of public Health, College of Health and Medical Sciences, Haranmaya University, Dire dawa, Ethiopia. ${ }^{2}$ Federal Police Hospital, Harar, Ethiopia.

Received: 30 May 2016 Accepted: 23 August 2016

Published online: 30 August 2016

\section{References}

1. Raatikainen K, Heiskanen N, Heinonen S. Transition from overweight to obesity worsens pregnancy outcome in a BMI-dependent manner. Obesity. 2006;14:165-71.

2. Nancy $F$, Janet $C$. Energy requirements during pregnancy and lactation. Public Health Nutr. 2005;8:1010-27.

3. Institute of Medicine. Weight gain during pregnancy: reexamining the guideline. Washington DC: National Academy Press; 2009.

4. WHO. Physical Status: The Use and Interpretation of Anthropometry. Geneva: WHO; 1995

5. Rhodes JR, Schoendorf KC, JD P. Maternal influences on child health: preconception, prenatal, and early childhood. Pediatrics. 2003;111:1181-5.

6. Lertbunnaphong T, Talungjit P, Titapant V. Does Gestational Weight Gain in Normal Pre-Pregnancy BMI Pregnant Women Re fl ect Fetal Weight Gain? J Med Assoc Thai. 2012;95:853-8

7. Thame MM, Jackson MD, Manswell IP, Osmond C, Antoine MG. Weight retention within the puerperium in adolescents: a risk factor for obesity? Public Health Nutr. 2010;13:283-8.

8. Stotland NJ, Haas JS, Brawarsky P, Jackso RA, Fuentes-Afflick E, Escobar GJ. Body mass index, provider advice, and target gestational weight gain. Obstet Gynecol. 2005;105:633-8.

9. WINKVIST A, STENLUND H, IIAKIMI M, DS M, DIBLEY MJ. Weight-gain patterns from prepregnancy until delivery among women in Central Java, Indonesia. Am J Clin Nutr. 2002;75:1072-7

10. Latifa M, Rachid R, Jalal K, Mariam K, Amina B. Body Mass Index, Gestational Weight Gain, and Obstetric Complications in Moroccan Population. J Pregnancy. 2013;2013:1-6.

11. Munim S, Maheen H. Association of Gestational Weight Gain and PrePregnancy Body Mass Index with Adverse Pregnancy Outcome. J Coll Physicians Surgeons Pakistan. 2012;22:694-8.

12. Rodrigues $\mathrm{PL}$, Lacerda EMA, Schlüssel MM, Spyrides MHC, Ka G. Determinants of weight gain in pregnant women attending a public prenatal care facility in Rio de Janeiro, Brazil: a prospective study, 2005-2007. Cad Saúde Pública. 2008:24:272-84.

13. Fraga ACSA, Filha MMT. Factors associated with gestational weight gain in pregnant women in Rio de Janeiro, Brazil, 2008. Cad Saúde Pública, Rio de Janeiro. 2014;30:633-44.

14. Maria I, Maria T, Anselmo O, Andressa G, Caroline B, Cristiane M, Juliana H, Patricia M, Rafael M, Silvia O. Socioeconomic, demographic and nutritional factors associated with maternal weight gain in general practices in Southern Brazil. Cad Saúde Pública, Rio de Janeiro. 2010;26:1024-34.

15. Michele D, Bruce B, Gilberto K, Maria I. Association of Second and Third Trimester Weight Gain in Pregnancy with Maternal and Foetal Outcome. Plos one. 2013;8:1-8.

16. Sharon J, Deborah B, Adam D, Alicia A, LaVette D, Emily O, and Gary D. Determinants of excessive gestational weight gain in urban, low income Women. Women's Health Issues. 2012;22:e439-e446.

17. Mei-Yueh C, Chun-Hua K, Kuei-Feng C. The effects of pre-pregnancy body mass index and gestational weight gain on neonatal birth weight in Taiwan. Int J Nurs Midwifery. 2010;2:28-34.

18. Mamu AA, Callaway LK, O'Callaghan MJ, William GM, Najman JM, Rosa A, Clavarino A, Lawlor DA. Associations of maternal pre-pregnancy obesity and excess pregnancy weight gains with adverse pregnancy outcomes and length of hospital stay. BMC Pregnancy Childbirth. 2011;11:62

19. Nelson ME, Rejeski WJ, Blair SN, Duncan PW, Judge JO, King AC, Macera CA, Castaneda-Sceppa C. Physical Activity and Public Health in Older Adults Recommendation From the American College of Sports Medicine and the American Heart Association. Circulation. 2007;116:1094-105.

20. Weisman CS, Hillemeier MM, Downs DS, Chuang CH, Dyer A-M. PRECONCEPTION PREDICTORS OF WEIGHT GAIN DURING PREGNANCY. Womens Health Issues. 2010;20:126-32.

21. Jiang H, Qian X, Li M, Lynn H, Fan Y, Jiang H, He F, He G. Can physical activity reduce excessive gestational weight gain? Findings from a Chinese urban pregnant women cohort study. Int J Behav Nutr Phys Act. 2012;9:12.

\section{Submit your next manuscript to BioMed Central and we will help you at every step:}

- We accept pre-submission inquiries

- Our selector tool helps you to find the most relevant journal

- We provide round the clock customer support

- Convenient online submission

- Thorough peer review

- Inclusion in PubMed and all major indexing services

- Maximum visibility for your research

Submit your manuscript at www.biomedcentral.com/submit 